\title{
Experimentation and thermodynamic representations of binaries containing compounds of low boiling points: Pentane and alkyl methanoates
}

\author{
Luis Fernández, Juan Ortega*, Gisela Sabater, Fernando Espiau \\ Laboratorio de Termodinámica y Fisicoquímica de Fluidos, Parque Científico Tecnológico, Campus Universitario de Tafira, Universidad de Las Palmas de \\ Gran Canaria, 35071 Las Palmas de Gran Canaria, Islas Canarias, Spain
}

\section{A R T I C L E I N F O}

\section{Article history:}

Received 13 September 2013

Received in revised form

14 November 2013

Accepted 15 November 2013

Available online 23 November 2013

\section{Keywords:}

VLE

LLE

Excess Properties

Alkyl methanoate

Pentane

Correlation

\begin{abstract}
A B S T R A C T
This work presents experimental mixing properties, $h^{\mathrm{E}}$ and $v^{\mathrm{E}}$, at several temperatures and the isobaric vapor-liquid equilibria (iso- $p$ VLE) at $101.32 \mathrm{kPa}$ for four binaries containing pentane and four alkyl (methyl to butyl) methanoates. Particular conditions are established to work with these solutions with highly volatile compounds, especially for the case of methyl methanoate + pentane system, for which a continuous feeding device is designed and constructed for measuring the densities. The mixing processes of the compounds chosen give rise to high values for the excess properties and also for the activity coefficients, since in addition to the known effects that arise in the binaries ester + alkane, in this case the associative effects caused by the HCOO- group, which diminish with increasing methanoate chain length are also relevant. The change in temperature produces slopes of opposite signs for the mixing properties, being $\left(\partial v^{E} / \partial T\right)_{p}<0$ and $\left(\partial h^{E} / \partial T\right)_{p}>0$. The systems comprised of methyl and ethyl methanoate with pentane present azeotropes with coordinates $\left(x_{\mathrm{az}}, T_{\mathrm{az}} / \mathrm{K}\right)$ situated at $(0.558,293.9)$ and $(0.218,306.5)$, respectively. The estimation of these coordinates and the iso- $p$ VLE by the UNIFAC method are acceptable but do not give good predictions of the $h^{\mathrm{E}}$ even less so for the LLE of the methyl methanoate + pentane system. For this binary, experimental data of all the properties are correlated with a mathematical procedure described using two models, one developed by us, and an extended form of the NRTL model. The latter does not represent the LLE data but shows the properties of isobaric equilibria, with acceptable results, while the proposed model, in addition to representing the binodal curve, gives a good representation of the $v^{\mathrm{E}}$ and of these properties derived from excess Gibbs function.
\end{abstract}

(c) 2013 Elsevier B.V. All rights reserved.

\section{Introduction}

In previous works, the mixing thermodynamic properties $\left(v^{E}\right.$ and $h^{E}$ ) were presented at several temperatures and also the isobaric vapor-liquid equilibria (iso-p VLE) for systems containing alkyl methanoate with hexane [1] and decane [2]. Another previous study [3] showed the associative influence of the HCOOgroup in systems containing alkyl methanoate + alkanes and the contribution of this effect in the structural model proposed and in the estimation of properties by one of the versions of the UNIFAC method [4]. In the literature, there are few studies on VLE measurements [5-7] for systems with methanoates and alkanes, although in the same line further investigations have been conducted on the specific behavior of ester + alkane systems [8-10]. This work presents measurements of $i s o-p$ VLE and of other mixing properties

\footnotetext{
* Corresponding author. Tel.: +34 928459548.

E-mail address: jortega@dip.ulpgc.es (J. Ortega).
}

for the first four alkyl (methyl to butyl) methanoates with pentane, $\mathrm{HCOOC}_{u} \mathrm{H}_{2 u+1}(u=1-4)+\mathrm{C}_{5} \mathrm{H}_{12}$, with the purpose of studying several aspects of these. These solutions are of special interest because of their peculiar behavior, mentioned briefly above, but also because of the difficulties of experimenting with formic acid derived esters.

Hence, studies of solutions containing pentane have certain experimental difficulties due to its low boiling point $\left(T_{b}^{\mathrm{o}}=\right.$ 309.22 K [11]), resulting in the corresponding limitations for use. Moreover, the presence of alkyl methanoates as a second component further hinders the formation of these solutions, especially methyl methanoate, ( $\left.T_{b}^{o}=304.90 \mathrm{~K}[11]\right)$, as the experimentation presents some complications that should be known a priori. Although the UNIFAC group contribution method [12] is used in this work to estimate the phase equilibria and enthalpies of binary solutions, exceptionally a previous estimation has been made to verify the behavior of the most peculiar case, such as the mixture of methyl methanoate + pentane. The result is shown in Fig. 1, where the presence of an azeotrope is observed at the minimum 


\begin{tabular}{|c|c|}
\hline$B_{i i}$ & second virial coefficients for pure component $i$ \\
\hline$B_{\mathrm{ij}}$ & cross second virial coefficients for mixture $i-j$ \\
\hline$c_{i}$ & weighting coefficients for property I, Eq. (19) \\
\hline GA & genetic algorithm \\
\hline$G_{i j}$ & parameters of NRTL model, Eq. (A2) \\
\hline$g^{E}$ & excess molar Gibbs function ( $\left.\mathrm{J} \mathrm{mol}^{-1}\right)$ \\
\hline$g_{i j}$ & coefficients of Eqs. (21) and (26) \\
\hline$\hat{g}_{L L E}^{E}$ & excess molar Gibbs function $\left(\mathrm{J} \mathrm{mol}^{-1}\right)$, for LLE \\
\hline$\hat{g}_{i j}$ & particular coefficients of Eq. (17) for LLE \\
\hline$h^{\mathrm{E}}$ & excess molar enthalpy $\left(\mathrm{J} \mathrm{mol}^{-1}\right)$ \\
\hline$h_{i j}$ & coefficients of Eq. (6) \\
\hline IL & ionic liquid \\
\hline$k_{v}$ & parameter of Eq. (2) \\
\hline$k_{h}$ & parameter of Eqs. (7)-(9) \\
\hline$k_{g}$ & parameter of Eq. (24) \\
\hline$N$ & number of experimental points \\
\hline $\mathrm{OF}$ & objective function \\
\hline$p$ & pressure $(\mathrm{kPa})$ \\
\hline$p_{i}^{o}$ & vapor pressure of component i \\
\hline$q_{k}$ & surface parameter of molecule $k$ \\
\hline$R$ & gas constant $\left(\mathrm{kJ} \mathrm{kmol}^{-1} \mathrm{~K}^{-1}\right)$ \\
\hline$r_{k}$ & volume parameter of molecule $k$ \\
\hline$s(m)$ & standard deviation of a property $m$ \\
\hline$T$ & temperature $(\mathrm{K})$ \\
\hline UCST & upper critical solution temperature (K) \\
\hline$v^{\mathrm{E}}$ & excess molar volume $\left(\mathrm{m}^{3} \mathrm{~mol}^{-1}\right)$ \\
\hline$v_{i j}$ & coefficients of Eq. (1) \\
\hline$x_{i}$ & molar fraction in the liquid phase for component $i$ \\
\hline$y_{i}$ & molar fraction in the vapor phase for component $i$ \\
\hline Y & expression given by Eq. (23) \\
\hline$z_{i}$ & active fraction of component $i$. \\
\hline \multicolumn{2}{|c|}{ Greek letters } \\
\hline$\alpha$ & non-random parameter of NRTL model (Eq. (A2)) \\
\hline$\alpha_{i}$ & $\begin{array}{l}\text { isobaric thermal expansion coefficient of compo- } \\
\text { nent } I\left(\mathrm{~K}^{-1}\right)\end{array}$ \\
\hline$\rho$ & density $\left(\mathrm{kg} \mathrm{m}^{-3}\right)$ \\
\hline$\phi$ & fugacity coefficient \\
\hline \multicolumn{2}{|r|}{ (A3) } \\
\hline$\gamma_{i}$ & activity coefficient of component $i$ \\
\hline$\tau_{i j}$ & coefficients of NRTL equation. \\
\hline
\end{tabular}

temperature at intermediate compositions and $p=101.32 \mathrm{kPa}$, of $T_{\mathrm{az}}=294.3 \mathrm{~K}$ (plane B), preventing the determination of mixing properties at this pressure over a wide range of compositions above the $T_{\mathrm{az}}$. At the standard working temperature $(298.15 \mathrm{~K})$, the azeotropic pressure is estimated as $119 \mathrm{kPa}$, plane A. Although these predictions may not be very accurate, they can be used to establish special working conditions to measure the properties of the binary methyl methanoate + pentane. Hence, for this system values of $v^{\mathrm{E}}$ and $h^{\mathrm{E}}$ have only been obtained at $T=291.15 \mathrm{~K}$ and data of $i s o-p$ VLE, carrying out the experimentation in special working conditions. For the other three binaries alkyl (ethyl to butyl) methanoate + pentane, in addition to the iso- $p$ VLE the $v^{\mathrm{E}}$ and $h^{\mathrm{E}}$ were determined at two temperatures 291.15 and $298.15 \mathrm{~K}$. For this group the literature contains azeotropic data [13] for solutions with $u=1,2$ and studies of liquid-liquid equilibria (LLE) [14] for the binary with $u=1$ at low pressure, whose curve is illustrated in Fig. 1, plane D.

Experimental data are correlated with a polynomial model on the excess Gibbs function of the form $g^{\mathrm{E}}=g^{\mathrm{E}}\left(p, T, x_{i}\right)[15,16]$. A simultaneous correlation with different properties is carried out generating a multiobjective optimization procedure which

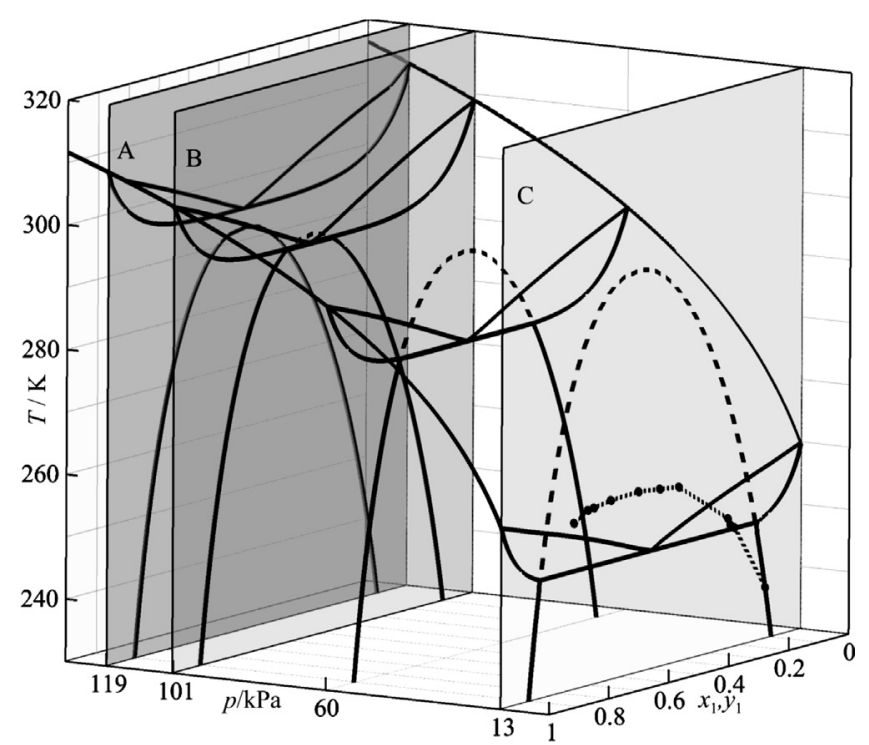

Fig. 1. Estimation by UNIFAC [12] of the curves of iso-p VLE (--) and iso-p LLE $(---)$ for the binary methyl methanoate + pentane. ( $)$ Experimental LLE points from Ref [14], at $p=13 \mathrm{kPa}$, plane C.

includes the residues of all of them. Hence, the procedure must be combined with another, more specific one, which also considers all the LLE data. The correlation procedure designed is also used to verify the capacity of a multiproperty fit for another model, NRTL [17], often used by chemical engineering researchers, which serves as a comparison. As mentioned, here we include the results obtained in the estimation of different properties of the systems containing methanoates using the UNIFAC group contribution model [12] that can be used to verify the predictive capacity of the method, when the set of parameters corresponding to the specific interaction $-\mathrm{HCOO} / \mathrm{CH}_{2}$ is used.

\section{Experimental section}

\subsection{Materials}

The products used were supplied by Sigma-Aldrich Co. and were all of the highest commercial purity. The quality of all the products was verified by a GC, model HP-6890N, with FID, giving slightly lower values of purity than those indicated by the manufacturer. Therefore, before use they were degasified with ultrasound and then stored over a $0.3 \mathrm{~nm}$ Fluka molecular sieve for several days to reduce the water contents. After this process, the purities were similar to, or higher than, those indicated by the manufacturer, see Table 1 . However, the physical properties of all the compounds were also measured, such as the density $\rho$, and the refractive index $n_{D}$, both at $T=298.15$ and $291.15 \mathrm{~K}$; and the normal boiling point $T_{b, i}^{\mathrm{o}}$. The values obtained for the four methanoates and pentane are shown in Table 2, where it can be appreciated that there are no significant differences between our values and those reported in the literature $[1,11,18,19]$, less than $0.3 \%$ for all cases. The water used in the calibration apparatus was double-distilled and degasified in our laboratory.

\subsection{Apparatus and procedures}

The excess molar enthalpies $h^{\mathrm{E}}$ of the binaries were measured in a MS80D Calvet conduction calorimeter by Setaram, at temperatures of 291.15 and $298.15 \mathrm{~K}$. The calorimetric system presents an excellent block thermal control accomplished only by heating. Hence, the workplace (with thermal, acoustic and electric 
Table 1

Description of the material used.

\begin{tabular}{|c|c|c|c|c|c|}
\hline Compound & Manufacturer & $\begin{array}{l}\text { Initial mass } \\
\text { fraction purity }\end{array}$ & Physical treatment & $\begin{array}{l}\text { Final mass } \\
\text { fraction purity }\end{array}$ & Analysis method \\
\hline Pentane & Aldrich & $>0.98$ & Molecular sieve & 0.992 & GC \\
\hline Methyl methanoate & Aldrich & $\sim 0.99$ & Molecular sieve & $>0.99$ & GC \\
\hline Ethyl methanoate & Aldrich & $\sim 0.960$ & Molecular sieve & 0.974 & GC \\
\hline Propyl methanoate & Aldrich & $\sim 0.968$ & Molecular sieve & $>0.97$ & GC \\
\hline Butyl methanoate & Aldrich & $>0.96$ & Molecular sieve & $\sim 0.974$ & GC \\
\hline Water & - & - & Double distillation & $\begin{array}{l}\text { Conductance } \\
<0.7 \mu \mathrm{S}\end{array}$ & Conductivity meter \\
\hline
\end{tabular}

insulation) was constantly maintained at a temperature lower than the experimentation temperature, at $\sim 16^{\circ} \mathrm{C}$, by a refrigeration system, for the time period of the experiments at $291.15 \mathrm{~K}$. The apparatus was calibrated by applying a joule effect to the laboratory cell with a resistance of $1000.2 \Omega$, using a power source from the same firm, model EJ3, which generates thermograms analogous to those of the mixing processes. The recording and subsequent treatment of data was carried out using the commercial software SEFTSOFT $^{\odot}$ supplied by Setaram, after first verifying that the real temperature chosen, $T=291.15 \mathrm{~K}$, had been reached in the cell. This was checked by first introducing a PT100 sensor in the experimental cell that is, filled with paraffin and connected to an ASL digital thermometer, model F200, with resolution of $\pm 1 \mathrm{mK}$. The purpose of this was to correct the temperature differences that arise between the $T$ programmed in PC and the response of the apparatus. As the calorimetric experimentation was carried out with a differential assembly, it was also verified that the thermal difference between the $\mid T$,laboratory- $T$,reference $\mid$ cells did not exceed $\pm 1 \mathrm{mK}$ in any case. Suitable experimental data of binaries could not be found to verify the accuracy of the measurements at $291.15 \mathrm{~K}$. For this purpose, measurements of the binary cyclohexane + hexane, considered as standard, were made at $291.15 \mathrm{~K}$ and the curve obtained presented mean differences of around 3\% compared to the one estimated by interpolation of the curves published in the literature $[20,21]$ at $298.15,288.15$ and $318.15 \mathrm{~K}$. The uncertainty in composition values was estimated to be lower than $\pm 3 \times 10^{-4}$. For the $h^{\mathrm{E}}$, the average uncertainty of the direct measurements was lower than $1 \%$. At $298.15 \mathrm{~K}$ the calorimeter was checked as indicated previously [27].

Refractive indices of the pure compounds were measured with a Zuzi 320 Abbe type refractometer with a uncertainty of \pm 0.0002 units and thermostatized with an external circulating water bath from Heto that provided excellent control of the water temperature and was used to maintain the apparatus at $(T \pm 0.02) \mathrm{K}$. The proper functioning of the apparatus was checked by measuring the $n_{\mathrm{D}}$ of ultrapure water at $298.15 \mathrm{~K}$, giving the exact value published in the literature [11].

Densities of the pure compounds and of mixtures of alkyl methanoate(1)+ pentane(2) were measured with an Anton Paar DMA-60/602 digital densimeter, with a reading error of $\pm 0.02 \mathrm{~kg} \mathrm{~m}^{-3}$. Temperature control at $(T \pm 0.01) \mathrm{K}$ was achieved using a 1166D Polyscience thermostatic waterbath. At the working temperatures the densimeter was calibrated with water and nonane as usual in our group. However, two different procedures were used for: (a) measurements made at the temperatures of 291.15 and $298.15 \mathrm{~K}$ for two of the binaries of alkyl (propyl, butyl) methanoate + pentane. For this purpose, samples of known composition were prepared by weighing, with $x \pm 0.0003$, and the $v^{\mathrm{E}}$ were determined from the densities of pure compounds and mixtures, with an uncertainty of $\pm 2 \times 10^{9} \mathrm{~m}^{3} \mathrm{~mol}^{-1}$, and (b) density measurements at the same temperatures for the alkyl (methyl, ethyl) methanoate + pentane. At $T=291.15 \mathrm{~K}$ the densimeter was

Table 2

Experimental properties ${ }^{\mathrm{a}}$ obtained for pure compounds. Densities and refractive indices were measured at atmospheric pressure and at two temperatures.

\begin{tabular}{|c|c|c|c|c|c|c|c|c|c|}
\hline \multirow[t]{2}{*}{ Compound } & \multirow{2}{*}{$\begin{array}{l}\text { CAS registry } \\
\text { number }\end{array}$} & \multicolumn{2}{|l|}{$T_{b, i}^{\mathrm{o}}(\mathrm{K})$} & \multirow[t]{2}{*}{$T(\mathrm{~K})$} & \multicolumn{2}{|c|}{$\rho\left(\mathrm{kg} \mathrm{m}^{-3}\right)$} & \multirow{2}{*}{$\begin{array}{l}10^{3} \bar{\alpha}\left(\mathrm{K}^{-1}\right) \\
\text { Lit. }\end{array}$} & \multicolumn{2}{|l|}{$n_{D}$} \\
\hline & & Exp. & Lit. & & Exp. & Lit. & & Exp. & Lit. \\
\hline \multirow[t]{3}{*}{ Pentane } & \multirow[t]{3}{*}{$109-66-0$} & \multirow[t]{3}{*}{309.04} & \multirow[t]{3}{*}{$309.22^{c}$} & $291.15 \rightarrow$ & 627.86 & $628.09^{e}$ & \multirow[t]{3}{*}{$1.65^{\mathrm{e}}$} & 1.3589 & $1.3568^{\mathrm{d}}$ \\
\hline & & & & \multirow{2}{*}{$298.15 \rightarrow$} & \multirow[t]{2}{*}{620.89} & $621.39^{c}$ & & \multirow[t]{2}{*}{1.3545} & $1.35472^{c}$ \\
\hline & & & & & & $621.10^{\mathrm{e}}$ & & & $1.3549^{f}$ \\
\hline \multirow[t]{4}{*}{ Methyl methanoate } & \multirow[t]{4}{*}{$107-31-3$} & \multirow[t]{4}{*}{304.70} & $304.90^{c}$ & \multirow{2}{*}{$291.15 \rightarrow$} & \multirow[t]{2}{*}{977.21} & $977.25^{\mathrm{e}}$ & \multirow[t]{4}{*}{$1.46^{\mathrm{b}}$} & 1.3452 & $1.3446^{\mathrm{d}}$ \\
\hline & & & $304.70^{\mathrm{b}}$ & & & $976.90^{\mathrm{b}}$ & & & \\
\hline & & & & \multirow{2}{*}{$298.15 \rightarrow$} & \multirow[t]{2}{*}{966.54} & $966.40^{c}$ & & 1.3415 & $1.3415^{c}$ \\
\hline & & & & & & $966.54^{\mathrm{b}}$ & & & \\
\hline \multirow[t]{4}{*}{ Ethyl methanoate } & \multirow[t]{4}{*}{$109-94-4$} & \multirow[t]{4}{*}{327.33} & $327.46^{c}$ & \multirow{2}{*}{$291.15 \rightarrow$} & \multirow[t]{2}{*}{923.40} & $924.59^{e}$ & \multirow[t]{4}{*}{$1.48^{\mathrm{b}}$} & 1.3614 & $1.3614^{\mathrm{d}}$ \\
\hline & & & $327.33^{\mathrm{b}}$ & & & $924.70^{\mathrm{b}}$ & & & \\
\hline & & & & \multirow[t]{2}{*}{$298.15 \rightarrow$} & \multirow[t]{2}{*}{914.35} & $915.30^{c}$ & & 1.3580 & $1.3575^{c}$ \\
\hline & & & & & & $915.16^{\mathrm{b}}$ & & & \\
\hline \multirow[t]{4}{*}{ Propyl methanoate } & \multirow[t]{4}{*}{$110-74-7$} & \multirow[t]{4}{*}{353.92} & $353.97^{c}$ & $291.15 \rightarrow$ & 907.97 & $907.70^{e}$ & $1.33^{\mathrm{b}}$ & 1.3778 & $1.3777^{d}$ \\
\hline & & & $353.92^{\mathrm{b}}$ & & & $907.80^{\mathrm{b}}$ & & & \\
\hline & & & & $298.15 \rightarrow$ & 899.86 & $899.60^{c}$ & & 1.3752 & $1.3750^{c}$ \\
\hline & & & & & & $899.08^{b}$ & & & \\
\hline Butyl Methanoate & $592-84-7$ & 380.13 & $379.30^{c}$ & $291.15 \rightarrow$ & 895.86 & $893.75^{e}$ & $1.21^{\mathrm{b}}$ & 1.3904 & $1.3904^{\mathrm{d}}$ \\
\hline & & & $380.13^{b}$ & & & $896.00^{\mathrm{b}}$ & & & \\
\hline & & & & $298.15 \rightarrow$ & 888.47 & $886.90^{c}$ & & 1.3872 & $1.3874^{c}$ \\
\hline & & & & & & $888.66^{b}$ & & & $1.3872^{\mathrm{b}}$ \\
\hline
\end{tabular}

\footnotetext{
a Uncertainties $u$ are: $u(T)= \pm 0.02 \mathrm{~K}, u(n)= \pm 0.0002$, and $u(\rho)= \pm 0.02 \mathrm{~kg} \mathrm{~m}^{-3}$.

b Ref. [1].

c Ref. [11].

d Interpolated from Ref. [11].

e Interpolated from Ref. [18].

f Ref. [19].
} 
Table 3

Coefficients $v_{i j}$, and $h_{i j}$, and standard deviations $s$, obtained in the correlation of $M^{E}=\vartheta\left(x_{i}, T_{i}\right)$, being $y^{\mathrm{E}}=v^{\mathrm{E}}$ or $h^{\mathrm{E}}$, using Eq. (1).

\begin{tabular}{|c|c|c|c|c|}
\hline & $\begin{array}{l}\text { Methyl methanoate } \\
(1)+\text { pentane }(2)\end{array}$ & $\begin{array}{l}\text { Ethyl ethanoate } \\
(1)+\text { pentane }(2)\end{array}$ & $\begin{array}{l}\text { Propyl methanoate } \\
(1)+\text { pentane }(2)\end{array}$ & $\begin{array}{l}\text { Butyl methanoate } \\
(1)+\text { pentane ( } 2)\end{array}$ \\
\hline \multicolumn{5}{|c|}{$y^{\mathrm{E}}=10^{9} v^{\mathrm{E}}\left(\mathrm{m}^{3} \mathrm{~mol}^{-1}\right)$} \\
\hline$v_{01}$ & & $1.232 \mathrm{E}+07$ & $1.079 \mathrm{E}+05$ & $8.832 \mathrm{E}+05$ \\
\hline$v_{02}$ & $2.145 E+04$ & $-3.281 \mathrm{E}+04$ & $5.006 \mathrm{E}+03$ & $-1.875 \mathrm{E}+02$ \\
\hline$v_{11}$ & & $-3.235 E+07$ & $2.577 \mathrm{E}+05$ & $2.228 \mathrm{E}+06$ \\
\hline$v_{12}$ & $-6.723 E+04$ & $9.430 \mathrm{E}+04$ & $-1.114 \mathrm{E}+04$ & $-1.513 \mathrm{E}+04$ \\
\hline$v_{21}$ & & $2.389 \mathrm{E}+07$ & $1.132 \mathrm{E}+06$ & $-9.827 \mathrm{E}+05$ \\
\hline$v_{22}$ & $9.116 E+04$ & $-7.186 \mathrm{E}+04$ & $2.399 \mathrm{E}+03$ & $8.367 \mathrm{E}+03$ \\
\hline$v_{31}$ & & - & - & - \\
\hline$v_{32}$ & $-4.433 E+04$ & - & - & - \\
\hline$k_{v}^{21}\left(p_{0}, T_{0}\right)$ & $1.87 \mathrm{E}+00$ & $1.43 \mathrm{E}+00$ & $1.19 E+00$ & $1.17 \mathrm{E}+00$ \\
\hline$\delta$ & $-1.30 \mathrm{E}-04$ & $1.70 \mathrm{E}-04$ & $3.20 \mathrm{E}-04$ & $4.40 \mathrm{E}-04$ \\
\hline$s\left(v^{\mathrm{E}}\right)$ & 5 & 31 & 25 & 15 \\
\hline \multicolumn{5}{|c|}{$y^{\mathrm{E}}=h^{\mathrm{E}}\left(\mathrm{J} \mathrm{mol}^{-1}\right)$} \\
\hline$h_{01}$ & - & $-2.412 \mathrm{E}+07$ & $-4.530 \mathrm{E}+06$ & $-1.958 \mathrm{E}+07$ \\
\hline$h_{02}$ & $1.135 \mathrm{E}+04$ & $8.981 E+04$ & $2.158 \mathrm{E}+04$ & $7.196 \mathrm{E}+04$ \\
\hline$h_{11}$ & - & $7.426 \mathrm{E}+07$ & $7.259 \mathrm{E}+06$ & $5.706 \mathrm{E}+07$ \\
\hline$h_{12}$ & $-1.079 E+04$ & $-2.602 E+05$ & $-3.069 E+04$ & $-1.985 \mathrm{E}+05$ \\
\hline$h_{21}$ & - & $-6.551 \mathrm{E}+07$ & $-1.730 \mathrm{E}+07$ & $-4.646 \mathrm{E}+07$ \\
\hline$h_{22}$ & $5.172 \mathrm{E}+03$ & $2.276 \mathrm{E}+05$ & $6.265 E+04$ & $1.605 E+05$ \\
\hline$k_{h}^{21}\left(p_{0}, T_{0}\right)$ & $1.68 \mathrm{E}+00$ & $1.33 \mathrm{E}+00$ & $1.12 \mathrm{E}+00$ & $9.16 \mathrm{E}-01$ \\
\hline$\delta$ & $-1.30 \mathrm{E}-04$ & $1.70 \mathrm{E}-04$ & $3.20 \mathrm{E}-04$ & $4.40 \mathrm{E}-04$ \\
\hline$s\left(h^{\mathrm{E}}\right)$ & 21 & 14 & 12 & 11 \\
\hline
\end{tabular}

calibrated with the same substances and the calibration values were $\rho=998.60 \mathrm{~kg} \mathrm{~m}^{-3}$ for water and $\rho=719.29 \mathrm{~kg} \mathrm{~m}^{-3}$ for nonane. In the case (b) in order to avoid evaporations, and especially to prevent the formation of an azeotropic solution, as indicated in the introduction for methyl methanoate + pentane, a simple device was built, which is detailed in Appendix A.1. The uncertainty of the ester mole fraction in the most unfavorable case was estimated to be $x \pm 0.001$.

The experimental iso- $p$ VLE apparatus used consists in a glass ebullometer of $60 \mathrm{~cm}^{3}$ operating dynamically with recirculation of both phases $[2,22]$. The pressure was controlled at $(101.32 \pm 0.02) \mathrm{kPa}$ with a DH controller/calibrator, model PPC2, and the temperature at equilibrium with a 6800 Comarks-Electonic digital thermometer equipped with two PT100, calibrated according to the ITS-90, and with a reading error of around $\pm 20 \mathrm{mK}$. To achieve the molar fractions of the solutions in both phases at equilibrium, samples of $\sim 2 \mathrm{ml}$ were taken of the two phases and their densities $\rho$ were measured (at $291.15 \mathrm{~K}$ for methyl methanoate + pentane and at $298.15 \mathrm{~K}$ for the other three systems). The compositions of the liquid phases $x$, and the vapor phases $y$, for the ester, were estimated by a recursive procedure with an equation of the type: $\rho \equiv \rho(x)=\left[\left(\rho_{1}-\rho_{2}\right) x+\rho_{2}\right]+x(1-x)\left(a x^{2}+b x+c\right)$, where $\rho, \rho_{1}$ and $\rho_{2}$ are, respectively, the density of the sample of each of the phases, and of the pure compounds. The constants $a, b$ and $c$ of this equation are obtained by correlating the $(x, \rho)$ values of samples prepared previously of known composition at a given temperature. In all cases the correlation coefficient was $r^{2}>0.99$. The uncertainty estimated for the compositions obtained for both phases was $x, y \pm 0.002$..

\section{Experimental results}

\subsection{Densities and excess molar volumes}

Table S1 in Appendices A-C (SI) compiles the experimental values of $\left(x_{1}, \rho, v^{\mathrm{E}}\right)$ determined at temperatures of $291.15 \mathrm{~K}$ and $298.15 \mathrm{~K}$ and at atmospheric pressure for the binaries $\left\{x_{1}\right.$ alkyl (methyl to butyl) methanoate $+x_{2}$ pentane $\}$. Because of the difficulties mentioned in the introduction, the $v^{\mathrm{E}}$ of the methyl methanoate + pentane system were not determined at $298.15 \mathrm{~K}$.
The coordinates $v_{i}^{\mathrm{E}}=\vartheta\left(x_{i}, T_{i}\right)$ for each system were correlated with the following equation:

$v^{E}\left(x_{1}, T\right)=z_{1}\left(1-z_{1}\right) \sum_{i=0}^{2} v_{i} z_{1}^{i} \quad$ where $\quad v_{i}=\frac{v_{i 1}}{T}+v_{i 2}$

and

$z_{1}\left(x_{1}, T\right)=\frac{x_{1}}{x_{1}+k_{v}^{21}(T)\left(1-x_{1}\right)}$

with $\quad k_{v}^{21}(T)=\frac{v_{2}^{o}\left(p_{0}, T\right)}{v_{1}^{o}\left(p_{0}, T\right)}=\frac{M_{2}}{M_{1}} \frac{\rho_{1}\left(p_{0}, T\right)}{\rho_{2}\left(p_{0}, T\right)}$

where $M_{i}, v_{i}^{o}$, and $\rho_{i}$, respectively, correspond to the molecular mass, the molar volume and the density of compound $i$ at $T$ and at a reference pressure $p_{0}$. Considering the definition of the isobaric thermal expansion coefficient, for a given compound $i$, the following relationship can be established:

$\rho_{i}\left(p_{0}, T\right)=\rho_{i}\left(p_{0}, T_{0}\right) \exp \left[-\alpha_{i}\left(T-T_{0}\right)\right]$

where $\alpha_{i}$ is a mean value in the temperature interval $\left[T_{0}, T\right]$. With Eq. (3), Eq. (2) can now be rewritten:

$$
\begin{aligned}
k_{\mathrm{v}}^{21}(T) & =\frac{M_{2}}{M_{1}} \frac{\rho_{1}\left(p_{0}, T_{0}\right)}{\rho_{2}\left(p_{0}, T_{0}\right)} \exp \left[\left(\alpha_{2}-\alpha_{1}\right)\left(T-T_{0}\right)\right] \\
& =k_{\mathrm{v}}^{21}\left(p_{0}, T_{0}\right) \exp \left[\delta\left(T-T_{0}\right)\right]
\end{aligned}
$$

being: $\delta=\alpha_{2}-\alpha_{1}$. The $\alpha_{i}$ for each of the compounds of this work have been obtained from the literature $[1,19]$, because in this study densities were measured only at two temperatures, taking $T_{0}=298.15 \mathrm{~K}$ and $p_{0}=101.32 \mathrm{kPa}$ as reference. With these values, a correlation of $v_{i}^{\mathrm{E}}=\vartheta\left(x_{i}, T_{i}\right)$ for each of mixtures recorded in Table S1 (SI) has been carried out, using a genetic algorithm (GA) and minimizing the standard deviation as,

$s\left(v^{E}\right)=\left[\frac{\sum_{i=1}^{n}\left[v_{i, \exp }^{E}\left(x_{i}, T\right)-v_{i, \text { cal }}^{E}\left(x_{i}, T\right)\right]^{2}}{N}\right]^{1 / 2}$

where $N$ is the number of experimental points. The values obtained for the parameters of Eq. (1) are shown in Table 3. With the aim 

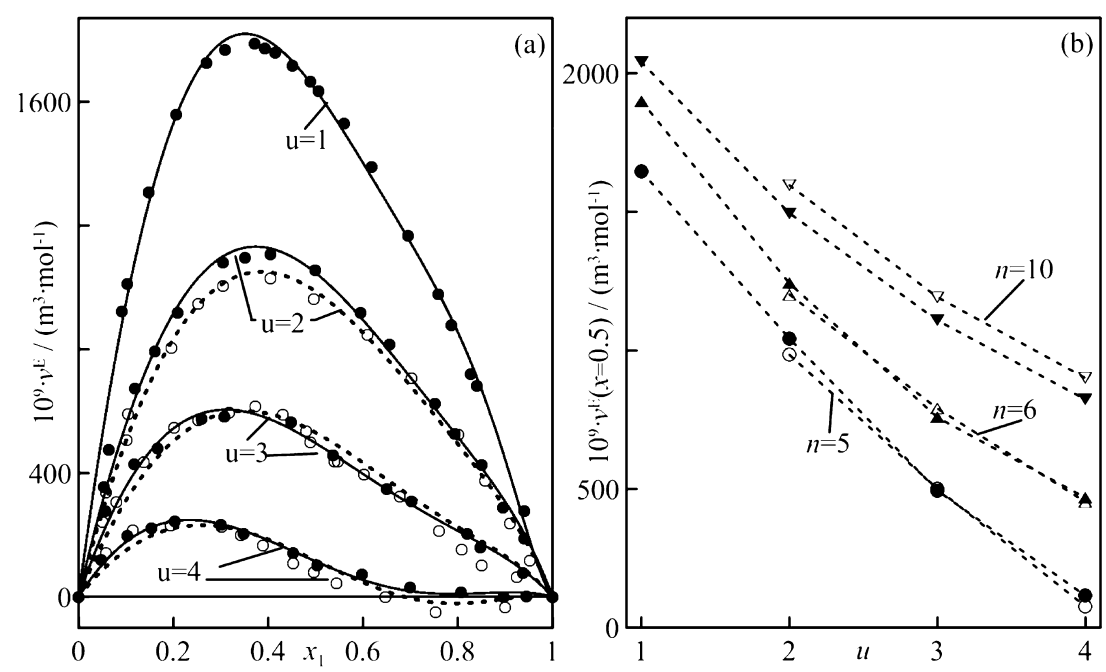

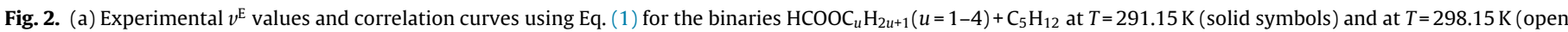

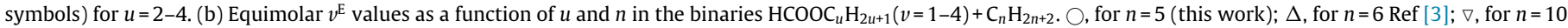
Ref [3]; $\bullet$ for $n=5$ (this work); $\boldsymbol{\Lambda}$, for $n=6 \operatorname{Ref}[1] ; \mathbf{v}$, for $n=10 \operatorname{Ref}[2]$.

of generalizing the use of an exponential form for the $k$ parameters, see Eq. (4), other more generic expression of the form: $k_{v}^{21}(T)=A \exp (B T)$ was tested. In this case, the global model has two new parameters, $A$ and $B$, which are determined in the same fitting procedure; the final representation is only negligibly better, so these results are not shown. Fig. 2a shows the distribution of experimental points and the fitted curve obtained by the indicated procedure at the two working temperatures, giving an acceptable correlation. Fig. $2 \mathrm{~b}$ represents the change in equimolar $v^{\mathrm{E}}$ of the set of systems $\mathrm{HCOOC}_{u} \mathrm{H}_{2 u+1}(u=1-4)+\mathrm{C}_{5} \mathrm{H}_{12}$ confirming some effects already observed in other works [1-3]. It is interesting to note the regular decrease in expansive effects with the increased alkanolic chain length of the methanoate, the increase in the number of $-\mathrm{CH}_{2}$ - groups reduces the Van der Waals attractions in the final state of the mixture compared to the initial state of the components. The distance between the dipoles associated with the HCOO-group in the mixture increases because of the invasion of the hydrocarbon, reducing the dipole-dipole effect, increasing the empty spaces and improving the accommodation; which lowers the $v^{\mathrm{E}}$ values. The variation in temperature produces $\left(\partial v^{\mathrm{E}} / \partial T\right)<0$, since $T$ influences the aforementioned effects in the final mixture, especially the bipolar moments, because the interactional distances increase with an improved interstitial accommodation of the molecules of the solution components.

\subsection{Excess molar enthalpies}

Table S2 (SI) shows the experimental values $\left(x_{1}, h^{E}\right)$, measured at $291.15 \mathrm{~K}$ and $298.15 \mathrm{~K}$ and at atmospheric pressure for the four binary mixtures $\mathrm{HCOOC}_{u} \mathrm{H}_{2 u+1}+\mathrm{C}_{5} \mathrm{H}_{12}(u=1-4)$, with the exception of the mixture with $u=1$ for the reasons given. The points obtained in the direct experimentation are shown in Fig. $3 \mathrm{a}$ at the two temperatures and were correlated with an adapted form of Eq. (1):

$h^{\mathrm{E}}\left(x_{1}, T\right)=z_{1}\left(1-z_{1}\right) \sum_{i=0}^{2} h_{i} z_{1}^{i} \quad$ where: $\quad h_{\mathrm{i}}=\frac{h_{i 1}}{T}+h_{i 2}$

the active fraction $z_{1}(x, T)$, referring to methanoate, is now defined by an expression similar to Eq. (2), but with a parameter $k_{h}^{21}$ which is related to $k_{v}^{21}$ by, see Ref. [1]:and

$$
z_{1}(x, T)=\frac{x_{1}}{x_{1}+k_{h}^{21}(T) x_{2}} \quad \text { with } \quad k_{h}^{21}(T)=\left(\frac{q_{2}}{q_{1}}\right)\left[\frac{r_{1}}{r_{2}} k_{v}^{21}(T)\right]^{2 / 3}
$$

where $r_{k}$ and $q_{k}$ are, respectively, the parameters of volume and surface of the molecule $k$, which are independent of temperature and are calculated by the individual contributions of the corresponding parameters (volume and surface) of the groups that constitute the molecule, see Bondi [23]. The relationship between $k_{h}^{21}$ and $k_{v}^{21}$ becomes evident when one considers the sphericity of the molecules. Although this hypothesis is not completely accurate, it can help to establish a first approach for the $k$ parameters of the mathematical model (to be consolidated in future works). Introducing Eq. (4) in Eq. (7) the latter is altered as follows:

$k_{h}^{21}(T)=k_{h}^{21}\left(p_{0}, T_{0}\right) \exp \left[\left(\frac{2}{3}\right)\left(\alpha_{2}-\alpha_{1}\right)\left(T-T_{0}\right)\right]$

where now:

$k_{h}^{21}\left(p_{0}, T_{0}\right)=\left(\frac{q_{2}}{q_{1}}\right)\left(\frac{r_{1}}{r_{2}}\right)^{2 / 3}\left[k_{v}^{21}\left(p_{0}, T_{0}\right)\right]^{2 / 3}$

Correlation of $h^{\mathrm{E}}=h^{\mathrm{E}}(x, T)$ data was done for each of the systems using the OF established with Eq. (5) and the procedure described. The results are shown in Table 3 and representations of the curves in Fig. 3a, where the variation in equimolar $h^{\mathrm{E}}$ values with the alkanolic chain length of the methanoate and with temperature are also shown, see Fig. 3b, being $\left(\partial h^{\mathrm{E}} / \partial T\right)>0$, although only for the interval [291-298] K. For the parameter $k_{h}^{21}$, the observation made previously in the case of volumes for $k_{v}^{21}$ is applicable; the correlation with a generic exponential expression did not improve the fit of $h^{\mathrm{E}}$ data.

For the mixtures studied the high values of the interaction energies are noteworthy, with values of $h^{\mathrm{E}}$ near $1900 \mathrm{~J} \mathrm{~mol}^{-1}$ for the mixtures of methyl methanoate at $291 \mathrm{~K}$. For the same mixture, the $v^{\mathrm{E}}$ are higher than $1.8 \times 10^{-6} \mathrm{~m}^{3} \mathrm{~mol}^{-1}$. These values reveal the different status of the pure compounds and those in the final mixture, as there is a clear difference between the values of both properties for the mixtures of methyl methanoate + pentane and for the other methanoates, mainly due to the loss of associative effects by hydrogen bonds as the R alkanolic chain of the methanoate HCOO-R increases, since these are more pronounced in the shortest chained methanoate. 

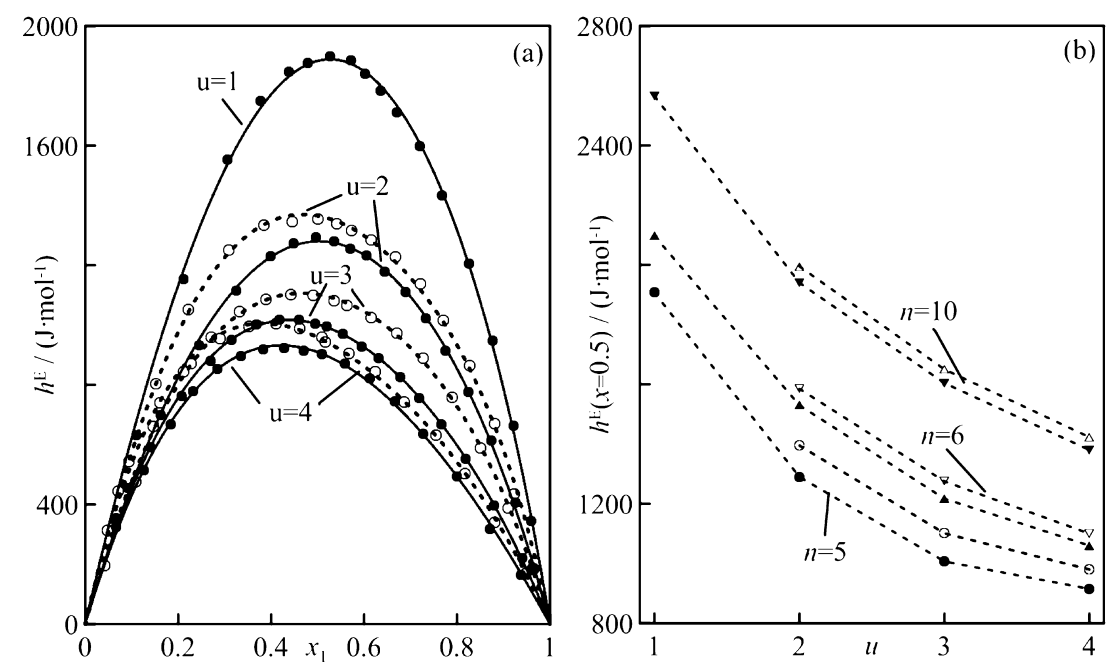

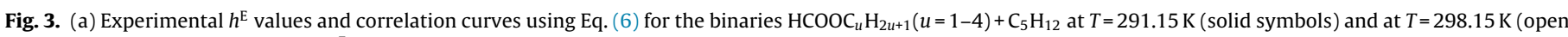

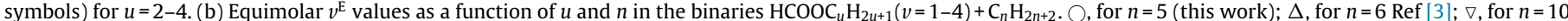
Ref [3]; $\bullet$, for $n=5$ (this work); $\boldsymbol{\Delta}$, for $n=6$ Ref. [1]; $\mathbf{v}$, for $n=10$ Ref. [2].
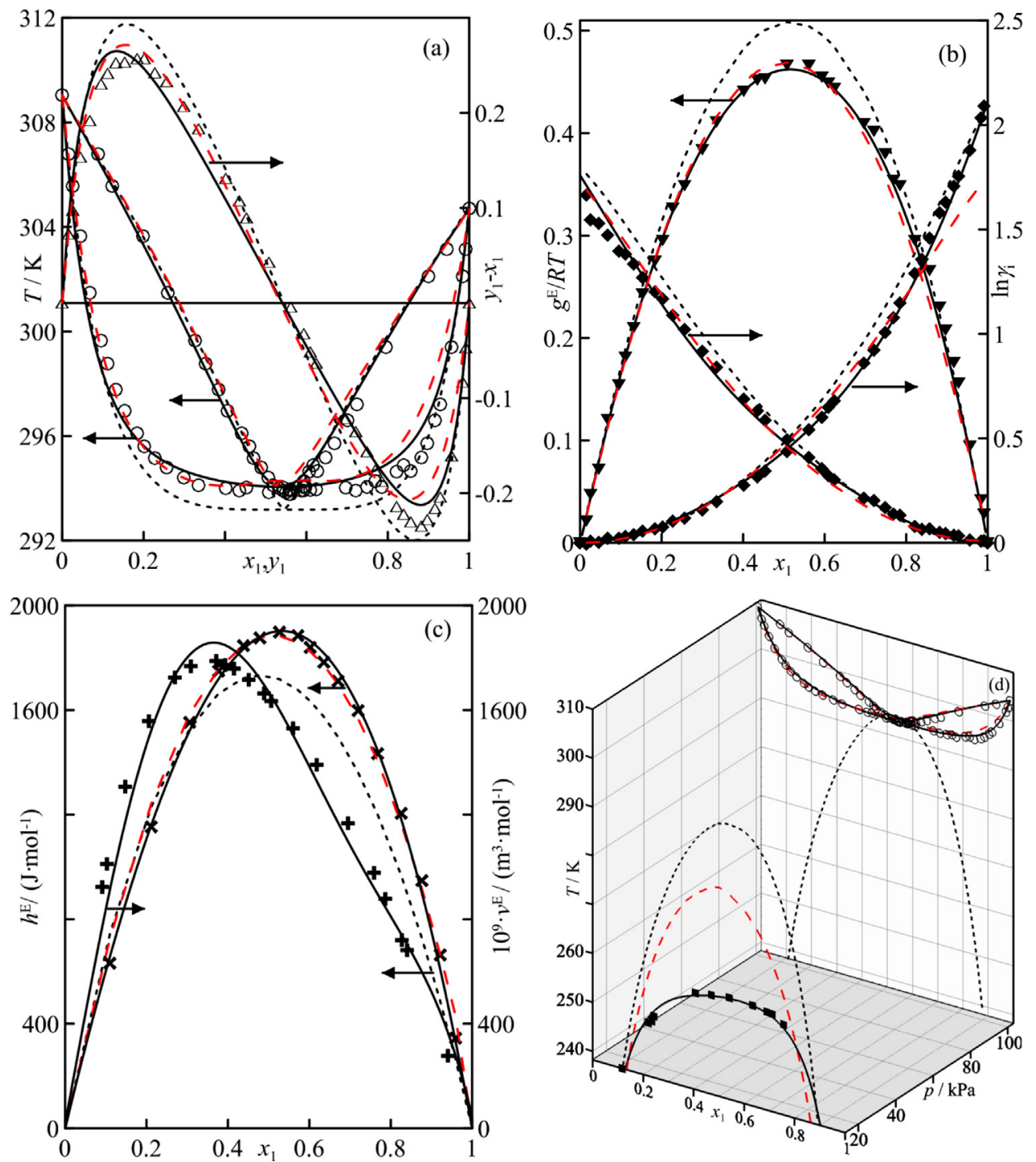

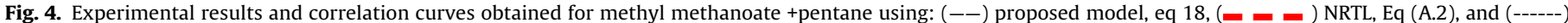

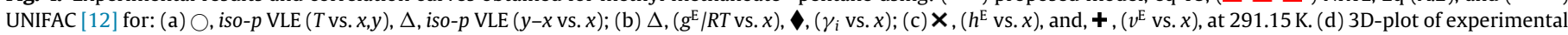
iso- $p \operatorname{VLE}(p, T, x, y)(\bigcirc)$, and those iso- $p \operatorname{LLE}(\boldsymbol{\square})$ from literature [14]. 

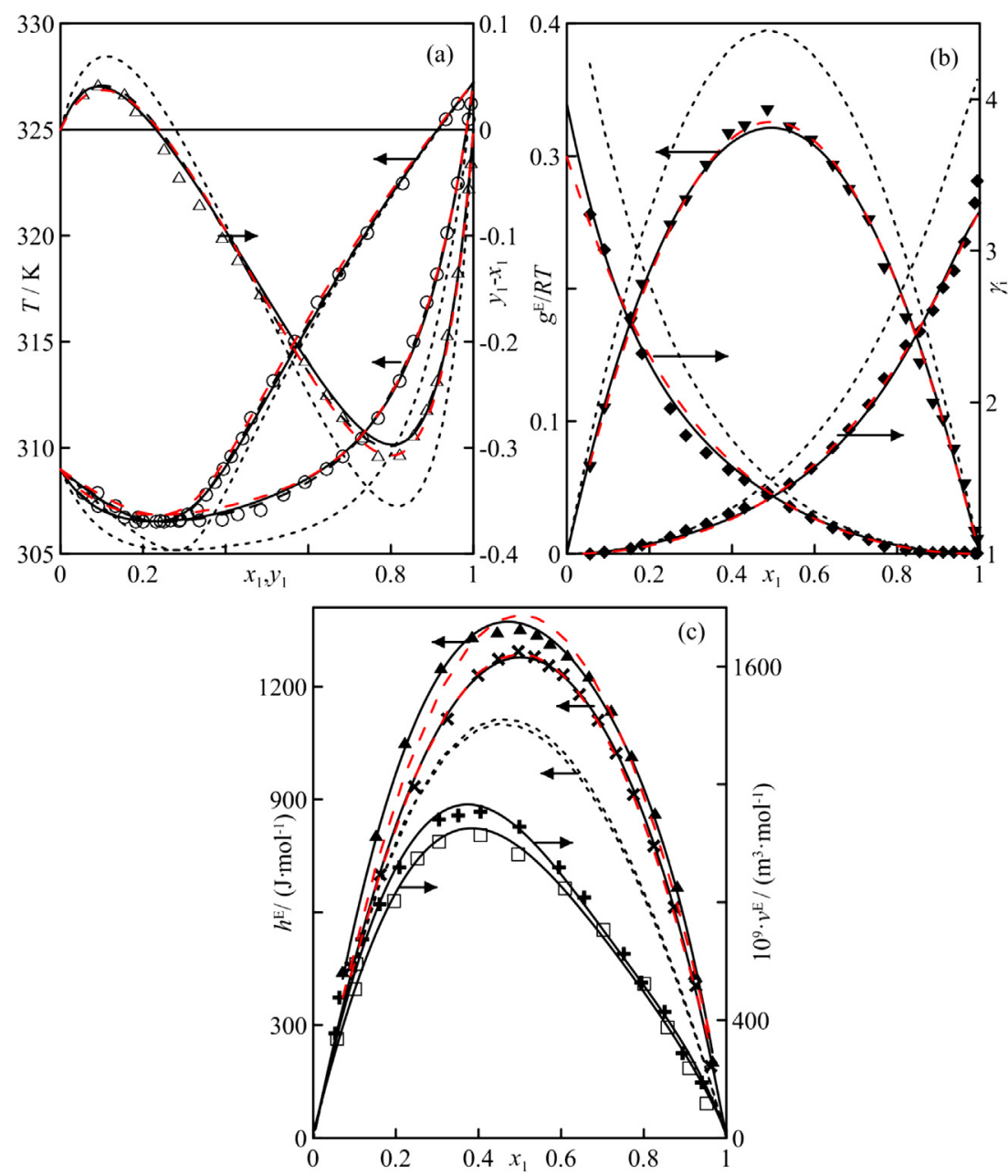

Fig. 5. Experimental results and correlation curves obtained for ethyl methanoate+ pentane using: (----) proposed model, Eq. (18), (- - - - ) NRTL, Eq. (A.2), and (------) UNIFAC [12] for: (a) O, iso-p VLE (T vs. $x, y), \Delta, i s o-p \operatorname{VLE}(y-x$ vs. $x)$; (b) $\mathbf{v},\left(g^{\mathrm{E}} / R T\right.$ vs. $\left.x\right), \boldsymbol{\downarrow}\left(\gamma_{i}\right.$ vs. $\left.x\right)$; (c) $\mathbf{X},\left(h^{\mathrm{E}}\right.$ vs. $\left.x\right)$, and, $\boldsymbol{+},\left(v^{\mathrm{E}}\right.$ vs. $\left.x\right)$, at $291.15 \mathrm{~K}, \boldsymbol{\Lambda},\left(h^{\mathrm{E}}\right.$ vs. $\left.x\right)$, and, $\square\left(v^{\mathrm{E}}\right.$ vs. $\left.x\right)$, at $298.15 \mathrm{~K}$.

\subsection{Isobaric vapor-liquid equilibria}

The iso-p VLE have been obtained at a pressure of $(101.32 \pm 0.02) \mathrm{kPa}$ for the four systems \{alkyl (methyl to butyl) methanoate + pentane , using the apparatus described in Section 2.1. The data obtained for temperature $T$ and composition of each phase, liquid $x$, and vapor $y$, at equilibrium are recorded in Table S3 (SI) and shown in Figs. 4a-7a. The activity coefficients of compound $i$ in the liquid phase $\gamma_{i}$, were calculated by the expression:

$x_{i} p_{i}^{o} \gamma_{i}=y_{i} p \frac{\hat{\phi}_{i}}{\phi_{i}^{\mathrm{o}}} \exp \left[-\frac{v_{i}^{\mathrm{o}}\left(p-p_{i}^{\mathrm{o}}\right)}{R T}\right] \quad i=1,2$

where $\hat{\phi}_{i}$, is the fugacity coefficient of species $i$ in solution, and $\phi_{i}^{o}$ and $p_{i}^{o}$ are, respectively, the fugacity coefficient as saturated vapor and the vapor pressure for component $i$. The molar volumes of each pure compound $i, v_{i}^{\mathrm{o}}$, are calculated in each equilibrium stage by a modified version of Rackett's equation [24] and the vapor pressures by Antoine's equation. The ratio $\left(\hat{\phi}_{\mathrm{i}} / \phi_{\mathrm{i}}^{\mathrm{o}}\right)$ is:

$\frac{\hat{\phi}_{i}}{\phi_{i}^{o}}=\exp \left[\frac{B_{i i}\left(p-p_{i}^{o}\right)+p\left(1-y_{i}\right)^{2}\left(2 B_{12}-B_{11}-B_{22}\right)}{R T}\right] \quad i=1,2$

The second virial coefficients for pure compounds $B_{i i}$, and mixtures $B_{i j}$, are calculated with the expressions proposed by
Tsonopoulos [25]. Numerical values of $\gamma_{i}$ and of the adimensional function $g^{\mathrm{E}} / R T$ are recorded in Table S3 (SI) together with their corresponding representations in Figs. $4 \mathrm{~b}-7 \mathrm{~b}$. The high values of $\gamma_{i}$ are noteworthy and indicate a high degree of interaction between the components of the mixture and deviation from the ideal, especially in the system with methyl methanoate (this is also reflected in high values for $h^{\mathrm{E}}$ and $v^{\mathrm{E}}$ ) and diminish with increasing length of the alkanolic portion of the methanoate. The same tendency has been observed in binaries with hexane [1] and with decane [2]. The global condition proposed by Fredenslund et al. [26], was used to verify the quality of the experimental VLE data for the four systems and all fulfilled the condition $\bar{\delta}=\sum\left(y_{i, \exp }-y_{i, \text { calc }}\right) / N<0.01$, so the thermodynamic consistency was considered to be positive for all of them.

Both in Table S3 (SI) of VLE data and also in the representations, azeotropic points were observed in two of the systems which are obtained by applying the boundary conditions: $x_{\mathrm{az}}=y_{\mathrm{az}}$ and $(\mathrm{d} T / \mathrm{d} x)_{\mathrm{az}}=(\mathrm{d} T / \mathrm{d} y)_{\mathrm{az}}$. Hence, for methyl methanoate + pentane, the coordinates $\left(x_{\mathrm{az}}, T_{\mathrm{az}}\right)$ were $(0.558,293.88 \mathrm{~K})$. For this binary, three sets of coordinates obtained by different procedures, even theoretically, are presented in the literature (see Gmehling et al. [13]). These are located at $(0.575,294.15 \mathrm{~K}),(0.573,294.85 \mathrm{~K})$ and $(0.574$, $294.95 \mathrm{~K})$, showing slight differences, of around $3 \%$ in composition, to the value obtained here, although the value for temperature is similar. The differences can be attributed to difficulties encountered in the experimental work with these systems, already mentioned in the introduction, and the age of the referenced values. On the 


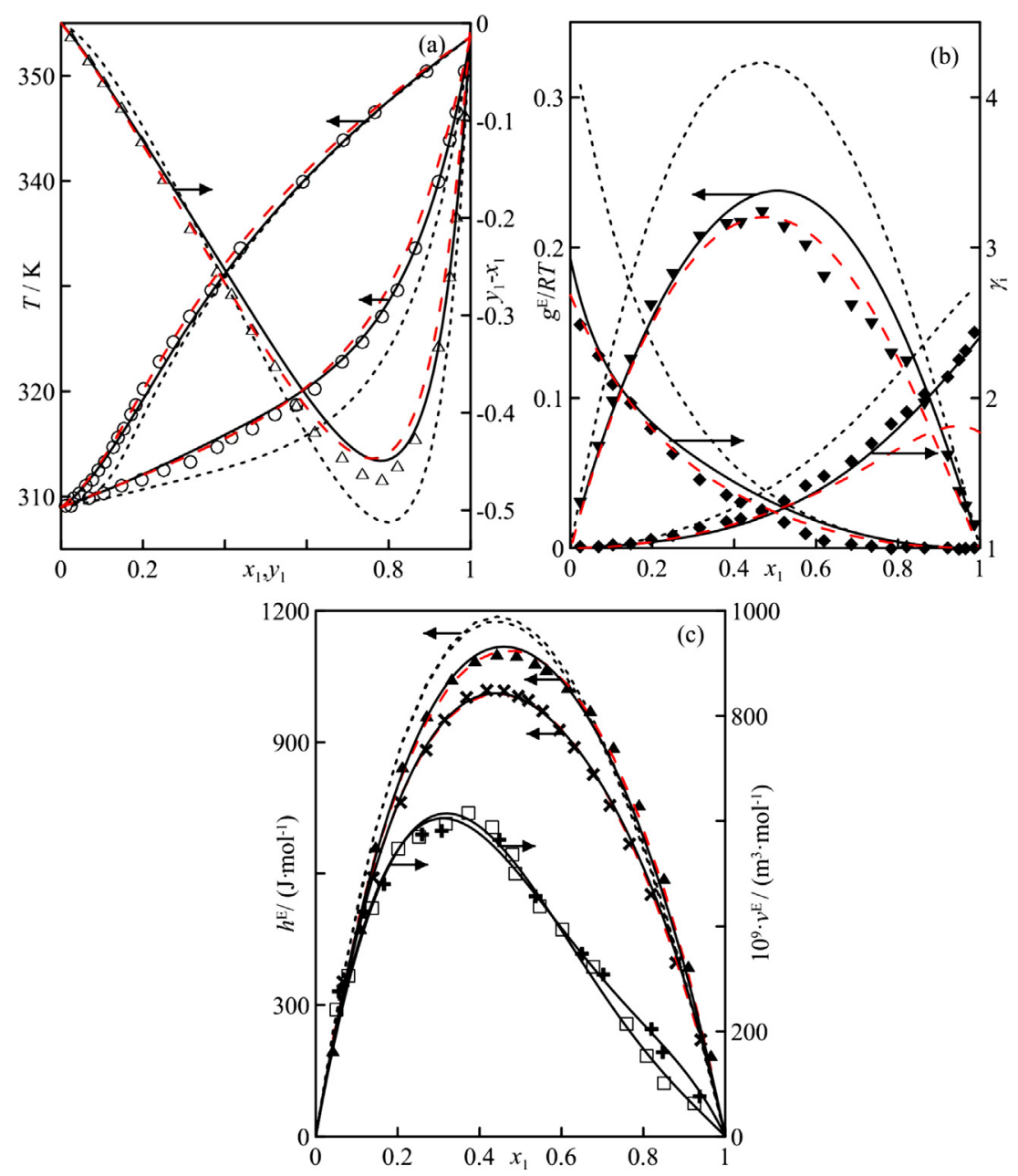

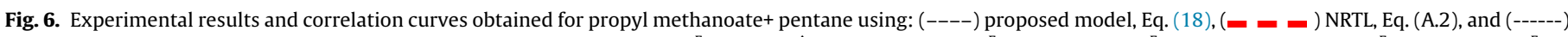

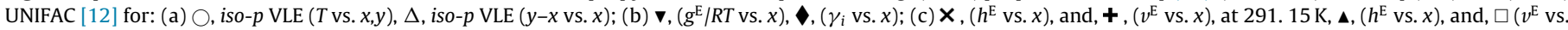
$x)$, at $298.15 \mathrm{~K}$.

other hand, the system of ethyl methanoate + pentane presents an azeotrope in solutions rich in pentane and the coordinates of the point are $(0.218,306.52 \mathrm{~K})$, this value is different to the theoretically estimated value [13] of $(0.289,305.65 \mathrm{~K})$. The other two systems are zeotropic.

\section{Multiproperty treatment of experimental data and prediction with UNIFAC}

Some systems contain compounds that are strongly incompatible at molecular level preventing the formation of homogeneous solutions, in other words, intervals of $p-T-x$ can exist where compounds of this type are immiscible and give rise to heterogeneous phases generating liquid-liquid equilibria (LLE). The zones of LLE that define the corresponding saturation curve may or not overlap with the VLE. If they do then a system of VLLE is generated, otherwise, two independent zones are obtained (each with two phases) for a single mixture [27], see Fig. 1. Direct modeling of systems that present LLE and VLE curves in the same plane of pressures, for example, is possible when there is a model for Gibbs function $g^{\mathrm{E}}$ that involves both phase equilibria, provided that the experimental values are thermodynamically validated. For the systems studied here, the literature [14] presents LLE data for the binary methyl methanoate + pentane at low pressure, $p=13 \mathrm{kPa}$, so the combined correlation of properties for this system with equilibria in different planes of pressure, must be differentiated and the procedure followed to do this is described below.

It is interesting to know the capacity of the UNIFAC group contribution method [12], to estimate properties of systems for which the main interaction corresponds to $\mathrm{HCOO} / \mathrm{CH}_{2}$, considered to be specific to methanoates. Without experimental points, the method predicts the behavior of VLE, LLE, and $h^{\mathrm{E}}$, etc. However, in a previous work [3] on enthalpies, the method greatly improved when associative effects due to hydrogen bonds of the methanoate molecules were introduced. Hence, a suitable modification in the UNIFAC version, proposed by Stathis and Tassios [28] gave rise to excellent estimations of the $h^{\mathrm{E}}$ values, although this has not been incorporated in the current version of the method [12]. The capacity of UNIFAC to predict the LLE of methyl methanoate + pentane system is discussed below.

\subsection{Multiproperty correlation of VLE, LLE and excess properties of methyl methanoate + pentane}

Here, only analyze the data treatment corresponding to the system methyl methanoate + pentane, for which the literature [14] presents LLE data, being necessary to recur to a mathematical procedure to guarantee the stability criteria of the phases. This procedure is based on obtaining theoretical values of the excess Gibbs function for the LLE, that are later related with the other properties existing for the solution, such as VLE, $h^{\mathrm{E}}$, etc. Hence, in an initial 

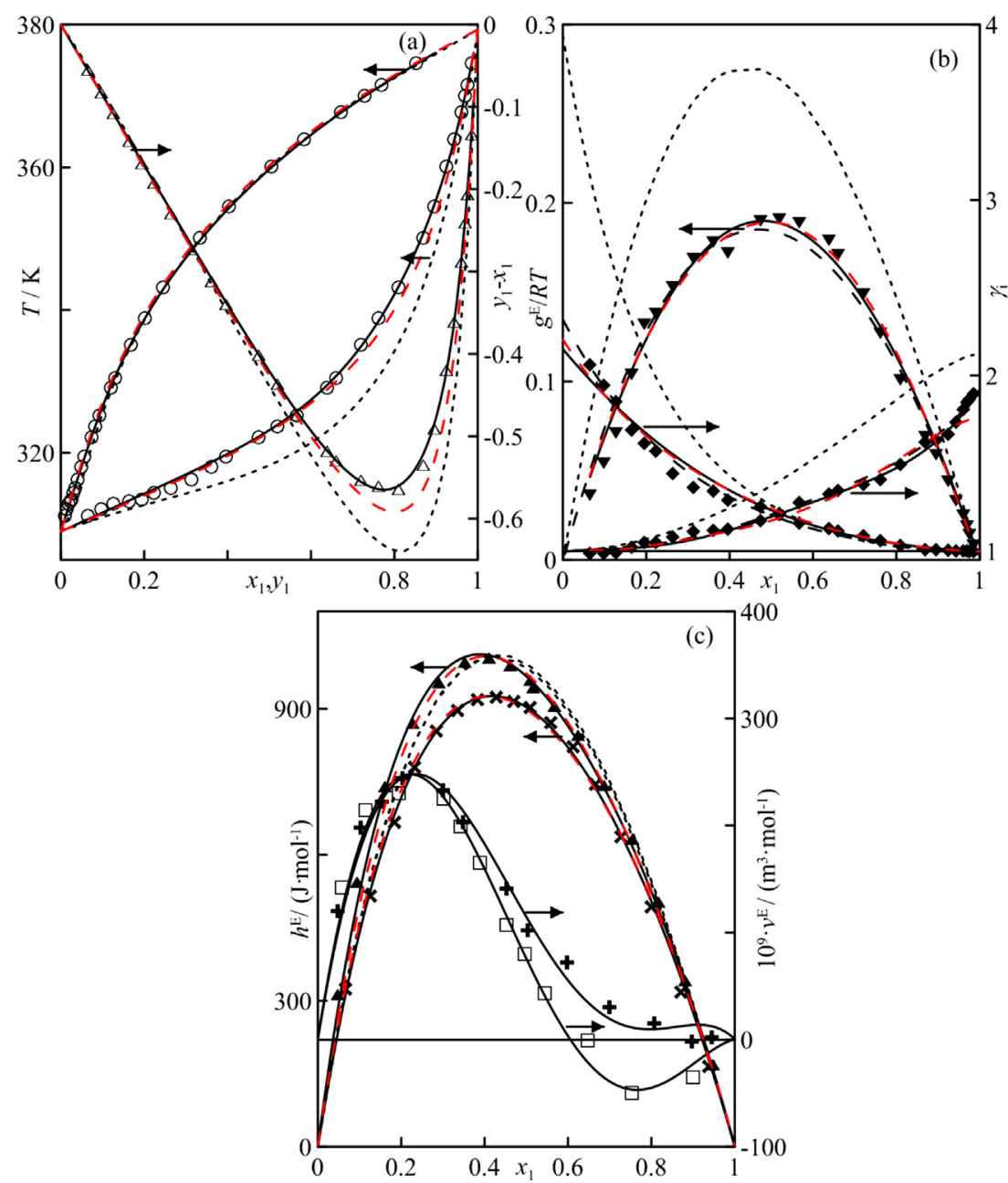

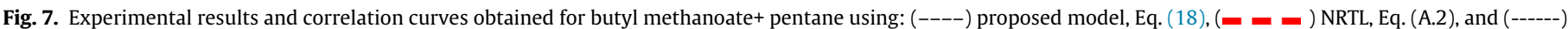

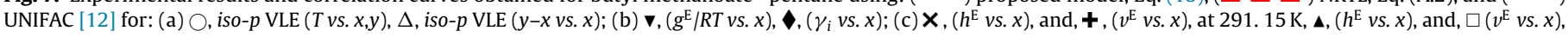
at $298.15 \mathrm{~K}$.

phase of the procedure, a function of the type $\hat{g}_{U \mathrm{UE}}^{\mathrm{E}}=\hat{\mathrm{g}}_{\mathrm{LE}}^{\mathrm{E}}(p, T, x)$ is obtained for the LLE, which guarantees the thermodynamic equilibrium and the stability of the phases. The equilibrium condition is established mathematically by the system of equations,

$$
\left.\begin{array}{l}
x_{1}^{\mathrm{I}} \gamma_{1}^{\mathrm{I}}=x_{1}^{\mathrm{II}} \gamma_{1}^{\mathrm{II}} \\
x_{2}^{\mathrm{I}} \gamma_{2}^{\mathrm{I}}=x_{2}^{\mathrm{II}} \gamma_{2}^{\mathrm{II}}
\end{array}\right\}
$$

indicating the isoactivity criterion in phases I and II. This generates theoretical values for the excess Gibbs function, constituting an additional term to Gibbs function for the ideal solution. So, the mixing Gibbs function, $\hat{g}_{\text {LLE }}$, which plays an important role when establishing a necessary and sufficient condition to ensure stability of the phases, being:

$$
\hat{g}_{\mathrm{LLE}}=\hat{g}_{\mathrm{LLE}}^{\mathrm{E}}+R T\left(x_{1} \ln x_{1}+x_{2} \ln x_{2}\right)
$$

When a concavity exists in the mixing Gibbs function, two phases appear and the condition of instability can be established mathematically for Eq. (13) by:

$\left(\partial^{2} \hat{\mathrm{g}}_{\mathrm{LLE}} / \partial x_{1}^{2}\right)_{p, T}<0$, or with Gibbs excess function

$\left(\frac{\partial^{2} \hat{g}_{\mathrm{LLE}}^{\mathrm{E}}}{\partial x_{1}^{2}}\right)_{p, T}+\frac{R T}{x_{1} x_{2}}<0$
The system of Eqs. (12) is satisfied in two steps. First, a correlation is carried out using the following objective function (OF), based on the isoactivity criterion,

$$
(\mathrm{OF})_{\gamma}=\sum_{i=1}^{m} \sum_{j=1}^{2}\left[\left(x_{j, i}^{\mathrm{I}} \gamma_{j, i}^{\mathrm{I}}-x_{j, i}^{\mathrm{II}} \gamma_{j, i}^{\mathrm{II}}\right)^{2}\right]
$$

using the experimental mole fractions of each of the species in the two phases. In the second step, the stability criterion of the phases, given by Eq. (14), is used optimizing a new OF that minimizes the discrepancies between the experimental compositions conjugated in each of the phases and those calculated using the parametric model chosen for the activity coefficients.

$(\mathrm{OF})_{x}=\sum_{i=1}^{m} \sum_{F=1}^{2}\left[\left(x_{i, \exp }^{F}-x_{i, \text { cal }}^{F}\right)^{2}\right]$

In this stage of the procedure, a set of parameters $\hat{g}_{i}$ is calculated generating values for the function $\hat{g}_{\mathrm{LLE}}^{\mathrm{E}}=\hat{g}_{\mathrm{LLE}}^{\mathrm{E}}(p, T, x)$, using a similar expression to Eqs. (1) and (6), which is adequate to describe the LLE. More specifically, the following expression is used:

$\hat{g}^{E}\left(x_{1}, p, T\right)=z_{1}\left(1-z_{1}\right) \sum_{i=0}^{2}\left(\frac{\hat{g}_{i 0}}{T}+\hat{g}_{i 1}\right) z_{1}^{i}$ 
In this way, the values generated for Gibbs function $\hat{g}_{\text {LLE }}$ form part of a database which also includes the other mixing properties: $\left[h^{\mathrm{E}}(x, T=291.15 \mathrm{~K}) ; g^{\mathrm{E}}(x, y, T) ; \hat{g}^{\mathrm{E}}(x, T) ; v^{\mathrm{E}}(x, T=291.15 \mathrm{~K})\right] \mathrm{a}$ set on which a global multivariable correlation is carried out using the following model:

$g^{E}\left(x_{1}, p, T\right)=z_{1}\left(1-z_{1}\right) \sum_{i=0}^{2}\left(g_{i 1}+g_{i 2} p T+\frac{g_{i 3}}{T}+g_{i 4} T^{2}\right) z_{1}^{i}$

Minimizing the following OF:

$\mathrm{OF}=c_{\mathrm{LLE}} s\left(\hat{g}_{\mathrm{LLE}}^{\mathrm{E}}\right)+c_{\mathrm{VLE}} s\left(g_{\mathrm{VLE}}^{\mathrm{E}}\right)+c_{H} s\left(h^{\mathrm{E}}\right)+c_{V} s\left(v^{\mathrm{E}}\right)$

and where the coefficients $c_{i}$ are weighting values for the different quantities participating in the fit and are also optimized by the correlation procedure to unify the weight of these quantities. The $s\left(y^{\mathrm{E}}\right)$ represent the standard deviations of each of the quantities $y^{\mathrm{E}}$, which are individually determined by:

$s\left(y^{E}\right)=\left[\sum_{1}^{N} \frac{\left(y_{i, \exp }^{E}-y_{i . \mathrm{cal}}^{E}\right)^{2}}{(N-1)}\right]^{1 / 2}$

being $N$ the number of experimental points of each property. In Eq. (18) the $g_{i j}$ are constants for each system and should be obtained by regression of the data set established previously. The function $z(x, T)$ is defined as in Eq. (2) but now, the $k$ parameter is referred here as $k_{g}^{21}$, and is calculated as described below.

By using the thermodynamic expressions that link the excess Gibbs function with volume and enthalpy, the following expressions are obtained:

$$
\begin{aligned}
v^{\mathrm{E}}= & \left(\frac{\partial g^{\mathrm{E}}}{\partial p}\right)_{T, x}=z_{1}\left(1-z_{1}\right) \sum_{\mathrm{i}=0}^{2} g_{i 2} T z_{1}^{i} \\
h^{\mathrm{E}}= & g^{\mathrm{E}}-T\left(\frac{\partial g^{\mathrm{E}}}{\partial T}\right)_{p, x}=z_{1}\left(1-z_{1}\right) \sum_{\mathrm{i}=0}^{2}\left(g_{\mathrm{i} 1}+\frac{2 g_{\mathrm{i} 3}}{T}+g_{\mathrm{i} 4} T^{2}\right) z_{1}^{\mathrm{i}} \\
& -T \frac{\partial z_{1}\left(x_{1}, p, T\right)}{\partial T} Y\left(x_{1}, p, T\right)
\end{aligned}
$$

where:

$$
\begin{aligned}
Y\left(x_{1}, p, T\right)= & \sum_{i=0}^{2}(i+1)\left[\left(g_{(i) 1}-g_{(i-1) 1}\right)+\left(g_{i+12}-g_{i 2}\right) p T\right. \\
& \left.+\frac{\left(g_{i+13}-g_{i 3}\right)}{T}+\left(g_{i+14}-g_{i 4}\right) T^{2}\right] z_{1}^{i}
\end{aligned}
$$

The values of the parameters $k\left(k_{g}^{21}, k_{h}^{21}, k_{v}^{21}\right)$ are different for each case, depending on the correlations $\left(g^{\mathrm{E}}, h^{\mathrm{E}}, v^{\mathrm{E}}\right)$. Hence, values of $k_{v}^{21}$ and $k_{h}^{21}$ are obtained for each system from Eqs. (4) and (8), respectively. For $k_{g}^{21}$, the values can be calculated by an exponential,

$k_{g}^{21}=k_{g 0}^{21}\left(p_{0}, T_{0}\right) \exp \left[B\left(T-T_{0}\right)\right]$

where $T$ is the equilibrium temperature at each point, $B$ is an adjustable parameter, $T_{0}$ is a reference temperature that is previously established and $k_{g 0}^{21}$, a chosen value at a reference conditions $\left(p_{0}, T_{0}\right)$. The value of $k_{g 0}^{21}$ is calculated by a rather artificial way as described: a subset of three or four values $\left(x, T, g^{\mathrm{E}}\right)$ of equilibrium states with small differences in $T$ (for the case of iso- $T$ VLE an analogous procedure would be created) are selected from among the experimental values. The coordinates chosen are correlated to the simplest form of the model

$g^{\mathrm{E}}=z_{1}\left(1-z_{1}\right) a_{0}$ obtaining a specific value of $k$ together with $a_{0}$ for a simple nonlinear regression. Hence, the reference temperature $T_{0}$ corresponds to the mean of the points used, the pressure $p_{0}$ is the working pressure in the isobaric case, and the parameter $k_{g 0}^{21}$ is the value of $k$ obtained in the fit, which is fixed for each mixture in Eq. (18).

After defining the multiproperty correlation procedure and the multiobjective function established by Eq. (19), a GA implemented in MATLAB ${ }^{\odot}$ is used to avoid the complexities generated with simultaneous correlation procedures based on the gradient method. The results obtained are shown in Table 4 for the binary methyl methanoate + pentane, together with the standard deviations of fit for each of the properties. The values corresponding to $k\left(\begin{array}{lll}k_{v}^{21} & y & k_{h}^{21}\end{array}\right)$ for volumes and enthalpies are those shown in Table 3 , as indicated in the text. Fig. 4 b shows the curves calculated by Eq. (18) for the excess Gibbs function $g^{\mathrm{E}}$ and the activity coefficients $\gamma_{i}$, while Fig. $4 \mathrm{c}$ represents the $h^{\mathrm{E}}$ and $v^{\mathrm{E}}$ curves. All representations can be considered to be acceptable. Finally, Fig. $4 \mathrm{~d}$ shows the values and the curves of fit of the phase equilibria (VLE and LLE), confirming the high capacity of the model and the effectiveness of the procedure to carry out a multiproperty correlation.

The mathematical procedure designed was also used for the NRTL model (see Appendix A.2) with the extended form proposed by Ko et al. [29], see Eq. (A3). The numerical results of the coefficients are shown in Table 4 and the corresponding representations in Fig. $4 \mathrm{~b}-\mathrm{d}$. In general, the representations are considered to be acceptable and the goodness of fit is very similar to the proposed model. However, this is not the case for the LLE, where NRTL extends the region of immiscibility far beyond the UCST of the data recorded by Franzosini et al. [14]. It is noteworthy that there are certain limitations in the application of the UNIFAC method [12] for estimating the properties of methyl methanoate + pentane, both in the iso- $p$ VLE and in the $h^{\mathrm{E}}$. Although the estimations by UNIFAC are lower than experimental values, the differences here, both in the compositions and the temperatures, can be assumed by the researcher. Hence, the coordinates of the predicted azeotrope $\left(x_{\mathrm{az}}=0.546, T_{\mathrm{az}}=293.20 \mathrm{~K}\right)$ are similar to the real values in spite of the experimental difficulties found for this system. However, the LLE that UNIFAC predicts for this mixture do not correspond with the data in the literature [14], see Fig. 4d.

\subsection{Combined correlation of VLE data and excess properties of alkyl (ethyl to butyl) methanoate + pentane}

No information is available on LLE data for systems of butyl, propyl and ethyl methanoate with pentane. Experimental data of $v^{\mathrm{E}}$ and $h^{\mathrm{E}}$ are provided at two temperatures (291 and $298 \mathrm{~K}$ ), Tables S1 (SI) and S2 (SI) (for methyl methanoate + pentane these properties were measured at only one temperature), as well as data of $i s o-p$ VLE, at $101.32 \mathrm{kPa}$, Table S3 (SI). Therefore, the model used in the previous case is not adequate, especially as it did not accurately reproduce the $v^{\mathrm{E}}$ at the two temperatures, so an extended version of Eq. (18) is now proposed with an additional term for pressure,

$g^{E}\left(x_{1}, p, T\right)=z_{1}\left(1-z_{1}\right) \sum_{i=0}^{2}\left(g_{i 1}+g_{i 2} p^{2}+g_{i 3} p T+\frac{g_{i 4}}{T}+g_{i 5} T^{2}\right) z_{1}^{i}$

and the expressions for the other properties, $h^{\mathrm{E}}$ and $v^{\mathrm{E}}$, are changed as follows:

$$
\begin{aligned}
h^{\mathrm{E}}= & z_{1}\left(1-z_{1}\right) \sum_{i=0}^{2}\left(g_{i 1}+g_{i 2} p^{2}+\frac{2 g_{i 4}}{T}-g_{i 5} T^{2}\right) z_{1}^{i} \\
& -T \frac{\partial z_{1}\left(x_{1}, T\right)}{\partial T} Y\left(x_{1}, p, T\right)
\end{aligned}
$$


Table 4

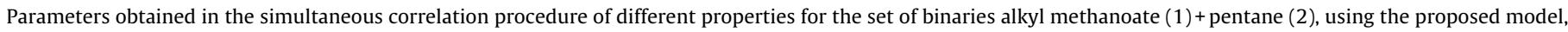
Eqs. (18) and (26), and NRTL, Eqs. (A2)-(A5). Standard deviations s, for each of the properties are also presented.

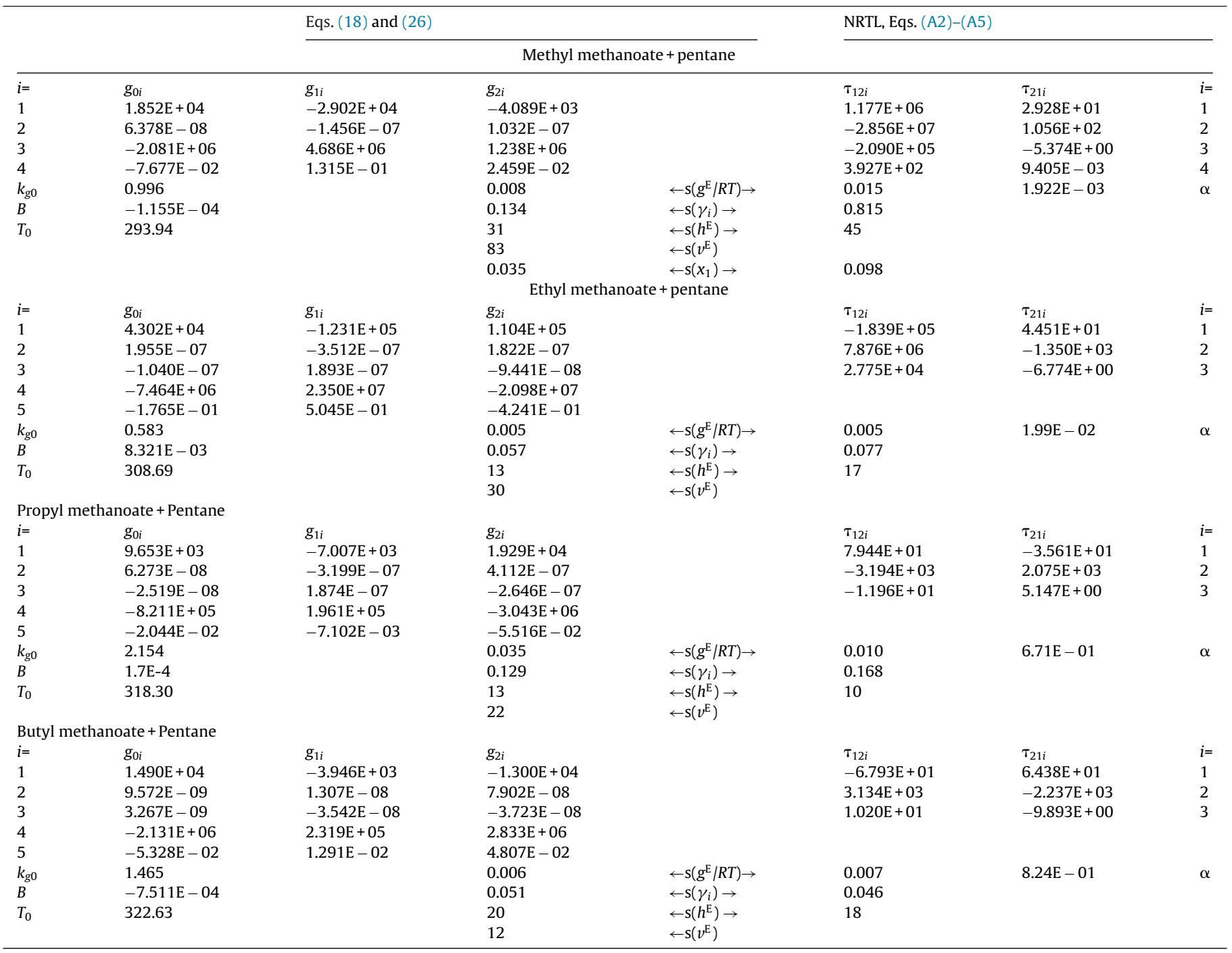

$v^{E}=\left(\frac{\partial g^{E}}{\partial p}\right)_{T, x}=z_{1}\left(1-z_{1}\right) \sum_{i=0}^{2}\left(2 g_{i 2} p+g_{i 3} T\right) z_{1}^{i}$

where $Y$ is also different to that presented by Eq. (23), giving

$$
\begin{aligned}
Y= & \sum_{i=0}^{2}(i+1)\left[\left(g_{i+11}-g_{i 1}\right)+\left(g_{i+12}-g_{i 2}\right) p^{2}+\left(g_{i+13}-g_{i 3}\right) p T\right. \\
& \left.+\frac{\left(g_{i+14}-g_{i 4}\right)}{T}+\left(g_{i+15}-g_{i 5}\right) T^{2}\right] z_{1}^{i}
\end{aligned}
$$

For the binaries of this group, values of the parameters $k\left(k_{g}^{21}\right.$, $k_{h}^{21}, k_{v}^{21}$ ) are calculated as indicated in Section 4.1. After introducing the model in the GA, the best values for the parameters $g_{i j}(p, T)$ of Eq. (26) are achieved using the multiobjective optimization procedure, with the OF from Eq. (19), described previously, but omitting the term corresponding to the LLE. The results of the simultaneous correlation for all the properties are recorded in Table 4 and the curves are represented in Figs. 5-7. Simultaneous correlation of all properties is also carried out with the NRTL model [17], using the version presented in Appendix A.2. In general, the fits made with the proposed model in this work and the NRTL model, are quite similar for this set, except for the propyl methanoate + pentane system, in which NRTL seems to produce a better representation, even with lower values of $s\left(y^{\mathrm{E}}\right)$. However, in Fig. $6 \mathrm{~b}$ a non-real maximum can be observed for $\gamma_{2}$ which results in a slight inflection for the adimensional Gibbs function.

For the three mixtures considered here, UNIFAC does not give a good prediction of the properties studied. The azeotropic point for the ethyl methanoate + pentane mixture is estimated at coordinates $\left(x_{\mathrm{az}}=0.277, T_{\mathrm{az}}=305.15 \mathrm{~K}\right)$, with a temperature $1.3^{\circ} \mathrm{C}$ lower than that obtained experimentally.

\section{Conclusions}

To expand our previous studies on solutions of alkyl methanoates + alkanes [1-3], iso- $p$ VLE, $h^{\mathrm{E}}$ and $v^{\mathrm{E}}$ were measured for four binaries empirically expressed by $\left\{\mathrm{HCOOC}_{u} \mathrm{H}_{2 u+1}+\mathrm{C}_{5} \mathrm{H}_{12}\right.$, $u=(1-4)\}$. The effects deduced by the experimentation are significant in these systems, and some are also common to other ester-alkane systems, such as interactions due to Van der Waals forces and dipole-dipole attractions. However, in the systems containing methanoate the associative effects due to hydrogen bonds are also important. This does not mean that these effects are not also produced in other esters, but they are more pronounced in 
the cases studied here. Combined effects give rise to significantly endothermic and expansive global results, in which the effects of the temperature is non-regular, since its variation does not affect the property in the same direction; in other words, a $\Delta T$ does not equally affect each of the three interactional effects mentioned previously. A positive variation in $T$ increases interactional distances, which also affects bipolar attractions, permitting a better accommodation of the molecules by reducing the final volume. Regarding the iso- $p$ VLE data, it is important to note the special conditions of the experimentation carried out with the low boiling-point systems (especially for methyl methanoate + pentane), obtaining results of excellent quality. The binaries of methyl or ethyl methanoate + pentane form azeotrope, as expected from the results obtained with systems containing hexane [1] and decane [2]. The VLE results give rise to high activity coefficients, especially in the system with methyl methanoate, indicating the high interactional degree of these mixtures which is also reflected in the excess quantities.

The multiproperty correlation is noteworthy and also the value of the model proposed to perform these operations, especially in the case of the methyl methanoate system with additional LLE data. The extended version of the NRTL model used gives a good correlation of the set of properties, but does not represent the LLE curves of the system, or the $v^{\mathrm{E}}$ since it does not include terms dependent on pressure. Finally, in reference to modeling, the UNIFAC model [12] represents iso- $p$ VLE data, but the discrepancy with experimental results steadily increases with increasing chain length of the alkanolic part of the ester. These differences are also reflected in the estimation of derived properties, especially in the $h^{\mathrm{E}}$ values at different temperatures. This occurs in spite of the model containing specific interaction parameters for the $\mathrm{HCOO} / \mathrm{CH}_{2}$ pair; therefore, improvement of the interaction parameters is an objective for future works.

\section{Acknowledgments}

Financial support has been provided by Spanish Government, Ministerio de Economia y Competitividadunder project no.CTQ2012-37114.

\section{Appendix A. New experimental device and NRTL model}

\section{A.1. Experimental continuous injection device and checking}

For working with low boiling-point compounds, as in the case of some mixtures elected, which form azeotropes with temperatures close to ambient, a device such as that designed for this experimentation and shown in Fig. A1, was used. The device was manufactured of glass and is the basis of a steel compact injection automatic system for future works.

The system works as a manually-operated continuous injector and consists in a small tank $\left(\sim 20 \mathrm{~cm}^{3}\right)$ that terminates in a tube in the shape of an inverted "T", with one outlet that connects directly to the entrance to the densimeter and the other that is soldered to a $3 \mathrm{~cm}^{3}$ glass syringe. The container is closed by means of a manually operated key, a teflon stem with a conical end that closes/opens the three vias of the "T", permitting the liquid flowing through the horizontal tube (pushed by the plunger of the syringe) enter the vibrating-tube of the densimeter returning the excess liquid to deposit on the top. This produces an almost continuous flow of a solution that changes its composition by the automatic addition of one of its components, from injector "I". The conical junctions connected to the densimeter are hermetic and held up by a support. The main corp of the device is thermostated with water circulating at a temperature which is slightly lower $(\approx 0.1 \mathrm{~K})$ than the densimeter.

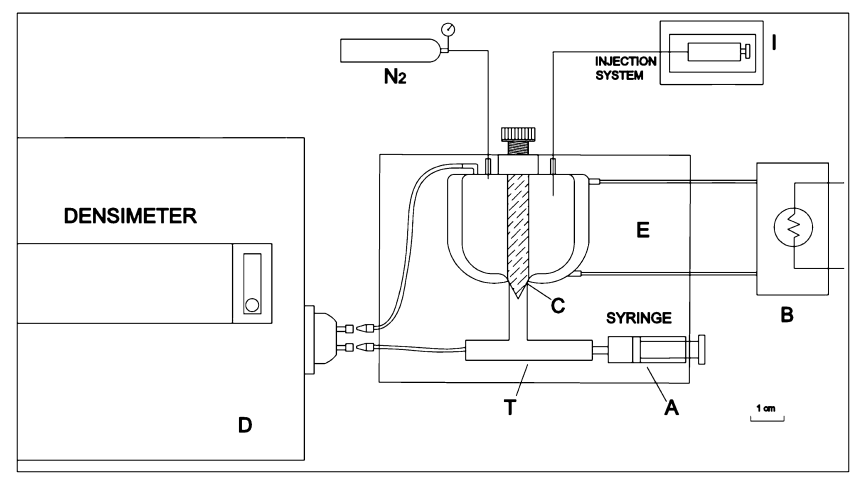

Fig. A1. Scheme of the continuous injection device built for density measurements of low boiling points compounds and mixtures. (A) glass syringe; (B) circulationthermostat; (C) teflon closing-rod; (D) densimeter-cell DMA-602; (E) isolated box; (I) injector controlled by PC.

In turn, the tank is immersed in another bigger one through which the water thermostated is flowing as shown in the scheme of Fig. A1. The measurement procedure consists in the following steps: (a) an exact known quantity of one of the components is injected into the tank and is pushed by the syringe plunger towards the densimeter, the teflon stem prevents the compound from flowing back into the tank. After waiting for the temperature reading to stabilize, the density value of the pure substance added is recorded; (b) with the automatic injector "I" controlled by computer, a known quantity of the second substance is added, the "T" valve is opened/closed and the syringe is used to circulate several times the solution through the densimeter to homogenize the mixture, until the densimeter reading remains constant. A small needle is used to inject a current of dry $\mathrm{N}_{2}$ into the container in order to get a uniform atmosphere. These operations are repeated as many times as necessary to obtain several points on the density and the corresponding $v^{\mathrm{E}}$ curve. The process is also repeated after changing the order of the substances added. Calculations of the ester compositions are estimated with an average uncertainty of \pm 0.001 .

The correct operation of the experimental device was first checked by reproducing the $v^{\mathrm{E}}$ data of a known mixture, such as benzene + cyclohexane at $298.15 \mathrm{~K}$, established as a standard by many authors. The temperature was selected in order to provide an effective comparison of the results obtained, since this is one of the mixtures most studied at 298.15 K. PC-guided continuous injection permits a large number of points to be obtained that are compiled in Table S4 (SI) and a comparison with reliable $v^{\mathrm{E}}$ data from the literature [30-38] showed average errors lower than 3\%, see Fig. A2. The experimental $\left(x_{1}, v^{\mathrm{E}}\right)$ data were correlated with a simplified form of Eq. (1), with $k_{v}^{21}$ for this mixture, and at the working temperature, taking a constant value of $k_{v}^{21}=2.216$. The final expression to represent the volumes of the mixture was:

$v^{\mathrm{E}}\left(x_{1}\right)=z_{1}\left(1-z_{1}\right) \sum_{i=0}^{2} v_{i} z_{1}^{i}$

while $z$ is given by Eq. (2). The coefficients obtained were: $v_{0}=3482$, $v_{1}=2305, v_{2}=1122$, with $s\left(10^{9} v^{\mathrm{E}}\right)=2 \mathrm{~m}^{3} \mathrm{~mol}^{-1}$.

\section{A.2. NRTL model}

In this work the NRTL model [17] was used with an adequate extended form for the parameters. That form is expressed by Eq (A3),

$\frac{g^{E}\left(x_{1}, T\right)}{R T}=x_{1} x_{2}\left(\tau_{21} \frac{G_{21}}{x_{1}+x_{2} G_{21}}+\tau_{12} \frac{G_{12}}{x_{1} G_{12}+x_{2}}\right)$ 


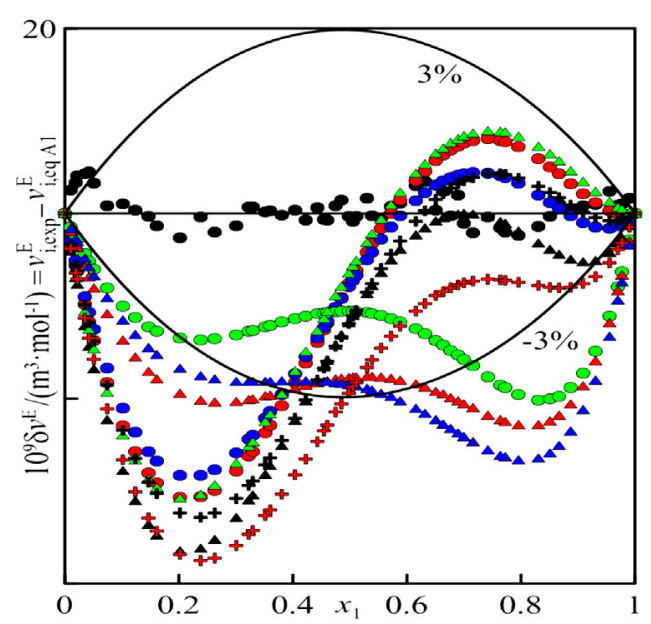

Fig. A2. Representation of residues, $\delta\left(v^{\mathrm{E}}\right)$, for the binary benzene(1)+ cyclohexane(2) calculated for $v^{\mathrm{E}}$ from experimental densities measured in device shown in Fig. A1 and those from literature: (๑) our values, ( ) Ref. [30],

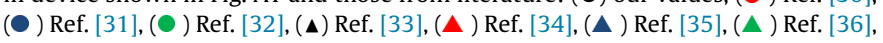
(+ ) Ref. [37], (+ ) Ref. [38]. (For interpretation of the references to color in this figure legend, the reader is referred to the web version of this article.)

$$
G_{i j}=\exp \left(-\alpha \tau_{i j}\right) \quad \tau_{i j}=\Delta g_{i j 1}+\frac{\Delta g_{i j 2}}{T+\Delta g_{i j 3}} \ln T+\Delta g_{i j 4} T
$$

From Eq. (A2) a mathematical expression for the excess enthalpies is

$$
\begin{aligned}
h^{\mathrm{E}}\left(x_{1}, T\right)= & R x_{1} x_{2}\left(\frac{\tau_{21}^{\prime} G_{21}}{x_{1}+x_{2} G_{21}}+\frac{x_{1} \tau_{21} G_{21}^{\prime}}{\left(x_{1}+x_{2} G_{21}\right)^{2}}\right. \\
& \left.+\frac{\tau_{12}^{\prime} G_{12}}{x_{1} G_{12}+x_{2}}+\frac{x_{2} \tau_{12} G_{12}^{\prime}}{\left(x_{1} G_{12}+x_{2}\right)^{2}}\right)
\end{aligned}
$$

where

$$
G_{i j}^{\prime}=\frac{d G_{i j}}{d(1 / T)} \quad \tau_{i j}^{\prime}=\frac{d \tau_{i j}}{d(1 / T)}
$$

\section{Appendix B. Supplementary data}

Supplementary data associated with this article can be found, in the online version, at http://dx.doi.org/10.1016/j.fluid.2013.11.026.

\section{References}

[1] J. Ortega, G. Sabater, I. de la Nuez, J.J. Quintana, J. Wisniak, J. Chem. Eng. Data 52 (2007) 215-225.

[2] J. Ortega, G. Sabater, Fluid Phase Equilib. 29 (2010) 18-31.

[3] J. Ortega, J. Placido, F. Toledo, M. Vidal, E. Siimer, J.L. Legido, Phys. Chem. Chem. Phys. 1 (1999) 2967-2974.

[4] P.J. Stathis, D.P. Tassios, Ind. Eng. Chem. Process Des. Dev. 24 (1985) 701-707.

[5] S.K. Ogorodnikov, V.B. Kogan, M.S. Nemtsov, Zh. Prikl. Khim. 34(1961) 581-585

[6] S. Galvan, J. Ortega, P. Susial, J. Peña, J. Chem. Eng. Jpn. 27 (1994) 529-534.

[7] J. Ortega, F. Espiau, R. Dieppa, Fluid Phase Equilib. 215 (2004) 175-186.

[8] J. Ortega, F. Espiau, J. Tojo, J. Canosa, A. Rodríguez, J. Chem. Eng. Data 48 (2003) $1183-1190$.

[9] J. Ortega, J.L. Legido, J. Fernández, M. López, L. Pías, M.I. Paz, Fluid Phase Equilib. 56 (1990) 219-234.

[10] F.J. Toledo-Marante, J. Ortega, M. Chaar, M. Vidal,J. Chem. Thermodyn. 32 (2000) 1013-1036.

[11] J.A. Riddick, W.B. Bunger, T.K. Sakano, Organic solvents: physical properties and methods of purification, in: Techniques of Chemistry II, fourth ed., WileyInterscience, New York, NY, 1986.

[12] J. Gmehling, J. Li, M. Schiller, Ind. Eng. Chem. Res. 32 (1993) 178-193.

[13] J. Gmehling, J. Menke, J. Krafczyk, K. Fisher, Azeotropic Data Part I, VCH, Weinheim, 1994.

[14] P. Franzosini, A. Geangu-Moisin, P. Ferloni, Z. Naturforsch. 25 (1970) 457-458

[15] J. Ortega, F. Espiau, Ind. Eng. Chem. Res. 42 (2003) 4978-4992.

[16] J. Ortega, F. Espiau, J. Wisniak, Ind. Eng. Chem. Res. 49 (2010) 406-421.

[17] H. Renon, J.M. Prausnitz, AIChE J. 14 (1968) 135-142

[18] TRC, Thermodynamic Tables of Non-Hydrocarbons \& Hydrocarbons, Thermodynamic Research Center, Texas A\&M University System, College Station, TX, 1993, Extant 2012.

[19] J. Ortega, J.S. Matos, Mater. Chem. Phys. 15 (1986) 415-426.

[20] K.N. Marsh, R.H. Stokes, J. Chem. Thermodyn. 1 (1969) 223-225.

[21] M.B. Ewing, K.N. Marsh, J. Chem. Thermodyn. 2 (1970) 295-296.

[22] J. Ortega, J. Peña, C. de Alfonso, J. Chem. Eng. Data 31 (1986) 339-342.

[23] A.A. Bondi, Physical Properties of Molecular Liquids, Cristals and Glasses, Wiley, New York, NY, 1968.

[24] C.F. Spencer, J. Danner, J. Chem. Eng. Data 17 (1972) 236-241.

[25] C. Tsonopoulos, AIChE J. 20 (1974) 263-272.

[26] Aa. Fredenslund, J. Gmehling, P. Rasmussen, Vapor-Liquid Equilibria Using UNIFAC: A Group Contribution Method, Elsevier, Amsterdam, 1977.

[27] L. Fernández, E. Pérez, J. Ortega, J. Canosa, J. Wisniak, Fluid Phase Equilib. 341 (2013) 105-123.

[28] P.J. Stathis, D.P. Tassios, Ind. Eng. Chem. Process Des. Dev. 24 (1985) 701-707.

[29] M. Ko, J. Im, J.Y. Sung, H. Kim, J. Chem. Eng. Data 52 (2007) 1464-1467.

[30] M. Takenaka, R. Tanaka, S. Murakami, J. Chem. Thermodyn. 12 (1980) 849-855.

[31] I.A. Weeks, G.C. Benson, J. Chem. Thermodyn. 5 (1973) 107-115.

[32] D.J. Stookey, B.D. Smith, H.M. Sallak, J. Chem. Thermodyn. 5 (1973) 741-751.

[33] R.H. Stokes, B.J. Levien, K.N. Marsh, J. Chem. Thermodyn. 2 (1970) 43-52.

[34] L.A. Beath, S.P. O'Neil, A.G. Williamson, J. Chem. Thermodyn. 1 (1969) 293-300.

[35] M. Diaz-Peña, D. Rodriguez-Cheda, Anal. Quim. Esp. 66 (1970) 637-643.

[36] J.R. Goattes, J.B. Ott, J.F. Moellmer, J. Chem. Thermodyn. 9 (1977) 249-257.

[37] M.K. Kumaran, M.L. Mc Glashan, J. Chem. Thermodyn. 9 (1977) 259-267.

[38] T.M. Letcher, J. Chem. Thermodyn. 4 (1972) 159-173. 